\title{
El papel del biofilm en el proceso infeccioso y la resistencia
}

\author{
María Teresa Herrera Mendoza Bac. Esp. \\ Docente - Investigador Universidad Colegio Mayor de Cundinamarca. \\ Recibido: 18-08-2004; Aceptado:24-09-2004
}

\begin{abstract}
Resumen
El biofilm es una población de células que crecen unidas a una superficie envueltas en una matriz de exopolisacaridos que las protege del ataque de los antibióticos. Más del $60 \%$ de todas las infecciones microbianas son causadas por biofilms, el aumento de la resistencia de estas comunidades a los antimicrobianos involucra varios mecanismos entre los que se incluyen: inactivación de los antibióticos por polímeros extracelulares o modificación enzimática, disminución de la tasa de crecimiento por limitación de nutrientes, cambios fenotípicos en las células bacterianas como resultado de la adquisición de genes de resistencia dentro del biofilm y la persistencia de un pequeño grupo de células en la comunidad bacteriana. En el futuro inmediato el pronóstico para el tratamiento y erradicación de los biofilms no es muy alentador. El desarrollo de nuevos medicamentos es necesario y urgente para contrarrestar las infecciones en las cuales el biofilm esta involucrado. La infección por biofilm se demuestra por síntomas que clínicamente recurren durante el tratamiento con antibióticos. El Instituto Nacional de Salud de E.U. publicó recientemente que más del $60 \%$ de todas las infecciones microbianas son causadas por biofilms, de igual manera se les atribuye el $60 \%$ de las infecciones nosocomiales, incrementando la estancia hospitalaria, los costos de atención y la mortalidad debido a su gran resistencia a los antimicrobianos mil veces mayor que la de las células que viven en forma planctónica. La presente revisión tiene por objeto ilustrar sobre la formación del biofilm y el papel de este en el proceso infeccioso.
\end{abstract}

Palabras Claves: biofilm, infección, resistencia, persistencia, antibioticos, crecimiento.

\section{Abstract \\ Infectious process and resistance biofilm role.}

Biofilm is a cell population which grows up together in a wrapped surface in a exopolysaccharide matrix which protects them of antibiotic attacks. More than $60 \%$ of all microbial infection is caused by Biofilm, to raise the resistance of these antimicrobial communities there are several mechanisms among others; antibiotic inactivity by extracellular polymerous or enzymatic alteration, grow rate diminished due to nutrient limitation, phenotypic changes in bacterial cells as a result of acquisition of resistance gene into biofilm and the persistence of a small cell group in bacterial community. The prognostic to treat and quit out biofilms is not encouraging in the immediate future. Is necessary and urgent to develop new medicines to counteract infectious on which 
biofilm is involved. Biofilm infection is evident with symptoms that clinically revert to antibiotic treatment. American Health Institute issued: "more than $60 \%$ of all microbian infectious are caused by biofilms", also a $60 \%$ is attributed to them in nosocomial infections, increasing in this way hospitable stay, attention fees and mortality; due to its large resistance to antimicrobial a thousand times more than cells which live in planktonic way. The objective of the current revision is to illustrate about biofilm formation and its role in the infectious process.

Key Words: biofilm, infection, resistance, persistence, antibiotics, infectious process.

La percepción de la bacteria como una forma de vida unicelular, la cual podemos cultivar en un medio líquido y analizarle su comportamiento, es el método más usado para el estudio de muchas actividades bacterianas como la patogénesis y la fisiología microbiana entre otras, pero la realidad es que el crecimiento planctónico puro es poco común, las bacterias frecuentemente se desarrollan en complejas comunidades y son las responsables del mantenimiento biogeoquímico de la biosfera (1).

Hasta hace poco la escasez de métodos para estudiar estas comunidades in situ impedía análisis detallados, afortunadamente los recientes avances en microscopía y técnicas de biología molecular han posibilitado el estudio en detalle de un área poco abordada de la biología microbiana. Observaciones directas de una amplia variedad de habitantes naturales ha permitido establecer que la mayoría de los microorganismos persisten unidos a las superficies dentro de un estructurado ecosistema denominado biofilm y no como organismos flotando libremente (2).

En la Figura 1 se ilustra el proceso de formación del biofilm: unión a la superficie, adherencia con otras células, formación de microcolonias y maduración dentro de una capa de exopolisacarido.

El biofilm se forma cuando la bacteria detecta ciertos parámetros ambientales; disminución o aumento de la disponibilidad de nutrientes y de hierro, cambios en la osmoralidad, el pH, la tensión de oxigeno y la temperatura, que disparan la transición de la forma

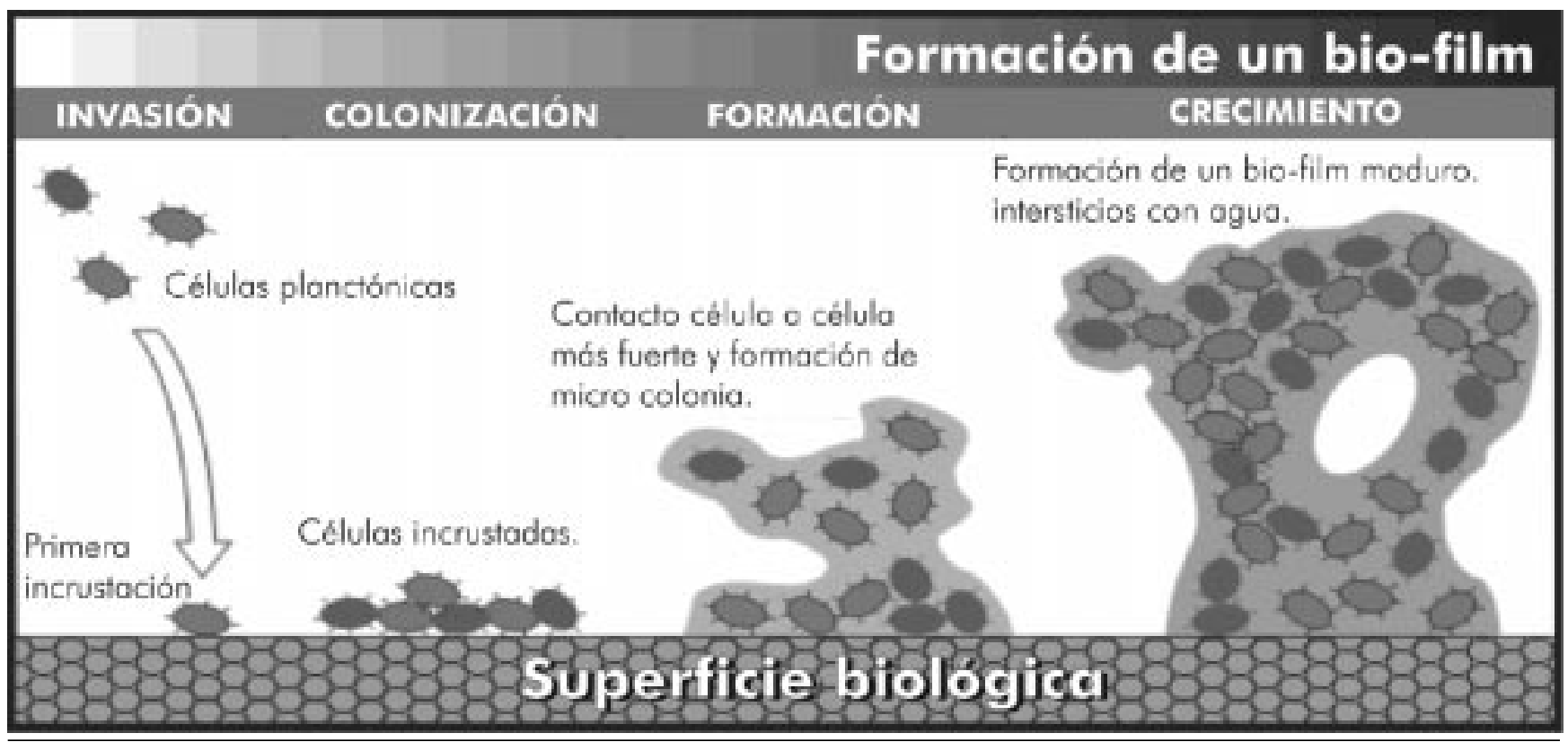

Figura 1. Formación y estructura de un biofilm. Disponible en: URL: www.alientoassist.com/libro/book_2.htm. 
planctónica a un crecimiento sobre una superficie. El ambiente que desencadena esta transición varía de un organismo a otro (3-7).

Las bacterias pueden colonizar una amplia variedad de superficies en ambientes bióticos o abióticos habitados por formas superiores de vida y espacios adversos $(2,8,9)$; su habilidad para persistir en la biosfera obedece en parte a su versatilidad metabólica y su plasticidad genotípica.

Un elemento para su adaptación es su capacidad para posicionarse en lugares en donde pueda propagarse. De los numerosos mecanismos de posicionamiento que han sido descritos en las bacterias, el más comúnmente observado es el movimiento flagelar y los diferentes métodos de traslocación superficial incluyendo contracción, deslizamiento y precipitación (10).

Las bases genéticas de la formación del biofilm en las cuales los flagelos y los pili son utilizados para adherirse, han sido ampliamente documentadas para algunas especies bacterianas incluyendo Escherichia coli, Pseudomonas aeruginosa, y Vibrio cholerae $(4,11,12)$.

Los tamizajes genéticos revelaron que la interacción inicial con la superficie es acelerada por la generación forzada de organelos semejantes al pili tipo IV y los flagelos, los cuales son utilizados por la bacteria para moverse a lo largo de la superficie en dos dimensiones hasta encontrar otras bacterias formando microcolonias, sobre las cuales se desarrolla el crecimiento $(4,11,12)$.

Existe evidencia que los genes transcritos en la fase planctónica son diferentes a los transcritos en el biofilm de acuerdo a la característica fenotípica requerida, por ejemplo, en Pseudomonas aeruginosa una vez se transcribe el gen alg, el cual es responsable de la producción del alginato, un exopolisacarido que cimienta la estructura del biofilm, la síntesis del flagelo es reprimida debido a que su presencia podría desestabilizar dicha estructura (13-15). Por otra parte algunos genes pueden expresarse en respuesta específica a la superficie que la bacteria ha escogido para establecerse y los genes que se expresan para adherirse a las superficies abióticas son diferentes dependiendo si estas son nutritivas o no $(4,11,16)$.

Otros mecanismos utilizados por las bacterias para fijarse a una superficie en respuesta a un ambiente son: la síntesis de celulosa, la cual ayuda a la unión a superficies de plantas, la modulación de su densidad en orden de posición sobre si mismas, formando diferentes niveles de columnas las cuales se sumergen en el agua para producir vesículas de gas, síntesis de carbohidratos o formar agregados (17), los magnetosomas, estructuras intracelulares consideradas de cristal o de mineral magnético rodeado por una membrana que causa el pasivo alineamiento de las células (18), la congregación la cual incrementa la interacción célula a célula así como la tasa de sedimentación celular; esta agrupación no solo favorece la unión a la superficie sino que brinda beneficios adicionales como la versatilidad fenotípica de las células hijas (19) y las adhesinas las cuales les permite adherirse no solo a superficies sino interactuar con otras bacterias (20-25).

La unión a la superficie es acompañada por la formación de microcolonias $\mathrm{y}$, finalmente, se da la maduración de estas dentro de una cápsula de exopolisacadido. Esta población de células que crecen adheridas a una superficie y son rodeadas por una matriz de exopolisacarido funcionan como un consorcio cooperativo de un modo complejo y coordinado, es decir con un ciclo de vida interdependiente, en el cual, cada una de las células actúa como parte integral de una población o comunidad se denomina biofilm (2,26).

Estructura del biofilm: el biofilm estructuralmente esta constituido por tres componentes: la masa de células la cual puede estar formada por una sola especie

Correspondencia: revistanova@unicolmayor.edu.co 
o por múltiples especies microbiológicas, los espacios intercelulares o canales, los cuales se han comparado con el sistema circulatorio de organismos superiores (2) y la matriz extracelular que lo rodea compuesta por una mezcla de exopolisacáridos, proteínas, ácidos nucleicos y otras sustancias.

El componente mejor estudiado es el exopolisacarido, muchas bacterias son capaces de producir exopolisacáridos (cápsulas) o excreciones celulares que rodean los ambientes. Es posible que el exopolisacarido juegue varios papeles en la estructura y función del biofilm ó que los exopolisacáridos tengan un papel diferente en comunidades microbiológicas similares bajo condiciones ambientales diferentes (27).

Entre los beneficios atribuidos a los exopolisacáridos como parte integral de la estructura organizacional se destaca el que actúan como un mecanismo de concentración de nutrientes, pero el mecanismo como tal por el cual desarrollan esta actividad es desconocido (28); previenen el acceso de ciertos agentes antimicrobianos o restringen la difusión de los componentes al interior del biofilm (29-31), contienen metales, aniones, cationes y toxinas que pueden ser la clave para la transferencia de estos al ecosistema $(32,33)$ y actúan como protec-

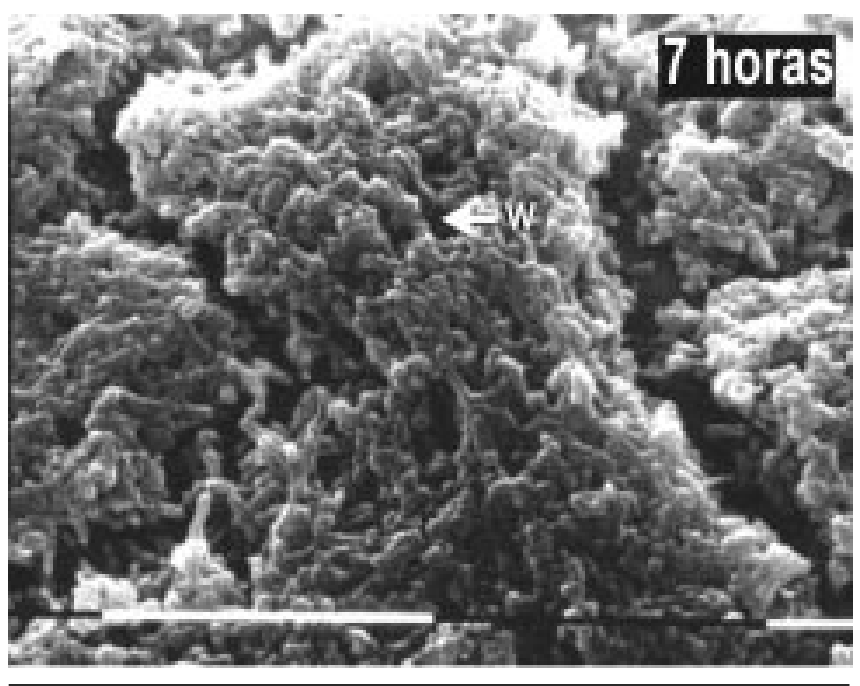

Figura 2. Microscopia electrónica del biofilm donde se observan la masa de células y los espacios que forman canales envueltos dentro de la matriz celular. (Tomada de URL: www.clermont.inra.fr/ proteome/ images/7jbis.jpg) tores de una gran variedad de condiciones de stress ambiental como rayos ultravioleta, cambios de $\mathrm{pH}$, shock osmótico y desecación (34).

El biofilm puede tener diferentes formas dependiendo de las condiciones ambientales bajo las cuales se formo. Las propiedades superficiales e intersuperficiales, los nutrientes disponibles, el tipo de bacterias que conforman la comunidad microbiana y la hidrodinámica hacen parte de las numerosas condiciones que lo pueden afectar (Figura 2) (35).

Los biofilms que crecen bajo corrientes terminales se observan poco uniformes y están constituidos por células redondas, irregulares, agregados separados por espacios intersticiales; los que crecen bajo corrientes turbulentas se observan disparejos, elongados, en serpentina y oscilan en la mayor parte del fluido y el biofilm estratificado y compacto crece sobre los dientes (36).

La biología microbiana afecta estructuralmente al biofilm en razón a que la población de células que en él se encuentran, presenta diferentes tasas de crecimiento lo cual se refleja en la heterogenicidad de los micronichos.

El manejo de la disponibilidad de nutrientes es diferente de acuerdo a la localización que tengan las células dentro de la comunidad, las que se encuentran más cerca de la microcolonia, se desempeñan mejor en el manejo de tensión baja de oxigeno.

En los biofilms que están formados por múltiples especies, puede resultar una asociación entre organismos metabólicamente cooperativos y la proximidad interespecies, facilita el cambio de sustratos y la distribución de productos metabólicos (36-38), la síntesis de moléculas como la acyl - homoserina lactones (acyl-HSLs) contribuye a la estructura tridimensional de éste (39).

La cercanía entre las células facilita la transferencia horizontal de genes, plásmidos o fagos, lo cual es importante para favorecer la diversidad genética de las comunidades microbianas naturales (40). 
La donación es el mecanismo más usado para la transferencia, los virus pueden causar lisis bacteriana de ahí que los fagos contribuyen a estructurar y reestructurar las comunidades $(41,42)$.

Papel del biofilm en la infección y la resistencia: la importancia del biofilm radica en su papel en la producción y degradación de materia orgánica, la degradación de contaminantes ambientales y la infección, en este último aspecto hace énfasis la presente revisión.

Una de las proezas de la medicina moderna como resultado de la investigación científica ha sido el progreso en el diagnóstico y el tratamiento de la enfermedad infecciosa con antibióticos, lo que ha permitido controlar efectivamente infecciones agudas. Sin embargo, hay dos excepciones: las bacterias que son innatamente resistentes a los medicamentos y las bacterias que residen dentro de biofilms que presentan una resistencia a los antimicrobianos mil veces mayor a las que viven en forma planctónica (43).

La infección causada por biofilm esta demostrada por síntomas que clínicamente recurren durante el tratamiento con antibióticos. Después de la adherencia inicial a los materiales biológicos la patogenia de la infección aparentemente involucra la interacción específica con diversos componentes tisulares y séricos del huésped, como el tejido conectivo, el colágeno, el lamineno y las proteínas séricas, como la fibronectina y la vitronectina permitiendo la colonización tisular y el establecimiento de infecciones de heridas, la colonización puede permitir que la bacteria invada las superficies mucosas alterando el flujo del calcio en las células epiteliales; liberando toxinas, proteasas y otros exoproductos. Esta infección es raramente resuelta por el sistema inmune del huésped.

El biofilm bacteriano libera antígenos y estimula la producción de anticuerpos, inhibe la proliferación de los linfocitos $\mathrm{T}$ y los monocitos periféricos por inducción de prostaglandina E2, e interfiere sobre la blastogénesis de las células B y la coagulación. También parece afectar adversamente la opsonización y la fagocitosis al inhibir la quimiotaxia, e induce la degradación e inhibe las actividades metabólicas dependientes de oxigeno de los leucocitos PMN, conduciendo a la muerte intracelular (44-48).

El Instituto Nacional de Salud de E.U. publicó recientemente que más del $60 \%$ de todas las infecciones microbianas son causadas por biofilms, de igual manera se les atribuye el $60 \%$ de las infecciones nosocomiales; incrementando la estancia hospitalaria, los costos de atención y la mortalidad.

El biofilm es la causa de infecciones comúnmente repetitivas del tracto urinario, causadas por E. coli y otros patógenos, infecciones de oído medio en niños causadas por Haemophilus influenzae, la formación de placa bacteriana, la gingivitis y la peridontitis causada por biofilms formados por Streptococcus, Fusobacterium y Porphyromona que produce la inflamación crónica de los tejidos que soportan la encía y pueden eventualmente generar la pérdida de los dientes y la infección pulmonar en pacientes con fibrosis quística causada por Pseudomonas aeruginosa, donde una infección con respuesta inflamatoria hiperactiva que destruye la función pulmonar puede generar la muerte del paciente $(44,45,49-51)$.

De igual forma, el papel del biofilm en la contaminación de los implantes médicos ha sido bien establecido en válvulas cardiacas, catéteres de línea central, intravenosos y urinarios que pueden conducir a bacteremia o sepsis, e infección de lentes de contacto $(52-56)$.

Mecanismos de resistencia del biofilm: la infección por el biofilm es difícil de erradicar dada su resistencia, definida como la habilidad de un microorganismo para crecer en presencia de un elevada concentración de antimicrobiano ó un pequeño grupo de cepas, en las cuales la concentración mínima inhibitoria (MIC) se ha incrementado. Pero en el biofilm no es necesario que se cumplan estos criterios convencionales, en él,

www.unicolmayor.edu.co 
se entiende como un incremento de la resistencia de las células atacadas (57).

Los mecanismos por los cuales se hacen resistentes aún no son completamente claros, pero se han considerado: la inactivación de antibióticos por polímeros extracelulares ó modificaciones enzimáticas, la baja disponibilidad de nutrientes lo que contribuye a una baja tasa de crecimiento, los cambios fenotípicos que adquiere la población bacteriana dentro del biofilm y la persistencia bacteriana; solos o en combinación estos factores son usados para explicar la supervivencia de las bacterias dentro de estas comunidades (29).

El biofilm en su interior contiene una gran cantidad de agua y solutos del tamaño de los antibióticos, por lo cual estos podrían difundirse fácilmente dentro de la matriz. Sin embargo, la movilidad física de los antibióticos en el biofilm no asegura que el antibiótico penetre dentro de este. La penetración es restringida debido a que la matriz de exopolisacáridos limita la difusión de sustancias y la unión del antimicrobiano proporcionando una efectiva resistencia a las células en su interior, contra grandes moléculas como antimicrobianos, proteínas, lisozimas y complemento.

La obstaculización de la difusión es probablemente efectiva contra pequeños péptidos antimicrobianos y sus análogos. Por otra parte, la carga negativa de los exopolisacáridos es muy efectiva en la protección celular contra antibióticos cargados positivamente como los aminoglicosídos, por restricción de la permeabilidad durante toda la unión $(31,58)$.

En otros casos, como en biofilms formados por Pseudomonas, se ha podido demostrar un sinergismo entre la difusión retardada del antibiótico y la degradación de este en el interior. La matriz de exopolisacáridos puede actuar como una barrera retardando la difusión del antimicrobiano lo que disminuye la concentración del antibiótico que ingresa al biofilm, para que en su interior enzimas semejantes a las lactamasas lo destruyan, logrando así una resistencia efectiva (59).

Correspondencia: revistanova@unicolmayor.edu.co
Dicho sinergismo es análogo al existente entre el interior de la membrana y la resistencia a fármacos por las bombas de exclusión que transportan antimicrobianos a través de esta barrera permeable, como los descritos para E. coli AcrAB-TolC localizado tras la membrana, que actuan como una bomba de multiresistencia semejante a la bomba de exclusión del Cloramfenicol CmlA localizada en el citoplasma, la cual capta al cloramfenicol y se lo presenta ala bomba Mex que se encarga de expulsarlo de la célula (59-61).

Otro factor considerado como responsable de la resistencia del biofilm es la disminución de la tasa de crecimiento, virtualmente todos los antibióticos son muy efectivos en el ataque rápido de las células en crecimiento, condición que es absolutamente requerida por algunos antibióticos para poder atacar. La Penicilina y la Ampicilina no atacan células que no estén en crecimiento y la tasa de ataque es proporcional a la tasa de crecimiento. Algunos de los más avanzados lactámicos, Cefalosporinas, Aminoglicosidos y Fluoroquinolonas pueden atacar células en fase estacionaría, pero ellos son indistintamente más efectivos en el ataque rápido de células en división.

En algunos biofilm la población de bacterias es heterogénea con respecto a la fase de crecimiento y cubre desde el espectro rápido hasta la fase metabólica inactiva. Las zonas de no crecimiento del biofilm están bien posicionadas y contribuyen a su supervivencia después del ataque del antibiótico (62). Otro mecanismo por el cual la disminución del crecimiento contribuye a la resistencia del biofilm es el gradiente químico que se establece dentro. El oxigeno es conocido por modular la acción de los aminoglucosidos y los gradientes de $\mathrm{pH}$ pueden impactar negativamente la eficiencia de los antibióticos (63).

Así mismo, las bacterias en respuesta y acoplamiento a fluctuaciones ambientales como cambios de temperatura, oxidación, baja disponibilidad de oxigeno y daños al DNA expresan genes, los cuales se transfieren entre ellas por donación mediante la 
conjugación logrando un mecanismo de supervivencia específico que explica su notable resistencia al ataque de un gran número de agentes, como el caso de la galactocidasa la cual es expresada en respuesta al Imipenen y la Piperamicina; o las bombas de difusión de multiresistencia a los medicamentos como la expresada por E. coli en respuesta al Cloramfenicol.

Muchas de dichas respuestas han sido bien caracterizadas molecular y genéticamente para cada caso en particular (64). La sensibilidad de la bacteria es usualmente restablecida cuando es separada del biofilm. Esta reversión rápida sugiere un mecanismo adaptativo de resistencia más que una alteración genética

El último factor considerado recientemente es la persistencia y la tolerancia, las bacterias del biofilm no solo evaden el ataque de los antibióticos, también resisten a los desinfectantes químicos como el hipoclorito y al glutaraldehido (65). Las células persistentes pueden constituir una pequeña fracción de la población total, pero estas pocas células son altamente protectoras semejantes al estado de espora de los Bacillus.

Los datos que soportan la persistencia del biofilm incluyen las siguientes hipótesis:

1. La dimensión bifásica del biofilm, en el cual gran parte de la población es atacada rápidamente pero una pequeña fracción de células no es afectada aún con un prolongado tratamiento con antibióticos.

2. Los genes que contribuyen a la persistencia codifican proteínas que actúan como circuitos reguladores que determinan la entrada y el éxito de este estado como la buena y específica respuesta protectora. Los genes (hip) para alto nivel de persistencia han sido descritos en E.coli (66).

3. Los antibióticos bacteriostáticos que inhiben el crecimiento paradójicamente contribuyen a la persistencia y a la preservación del biofilm; la persistencia depende de la dosis del antibiótico y del tiempo de duración del ataque.
Según estas consideraciones, se podría afirmar, que el uso de un antibiótico en su concentración bactericida mínima en el tratamiento de una infección causada por biofilm, resultaría en el decrecimiento del $99.9 \%$ del número de células vivas, lo que clínicamente resultaría satisfactorio ya que generalmente el sistema inmune colabora con el antibiótico limpiando el remanente de la población de células persistentes.

Cuando el sistema inmune no opera, la persistencia se convierte en un grave problema, como en la meningitis recalcitrante por Streptococcus pneumoniae ya que los componentes del sistema inmunológico no tiene accesibilidad al fluido espinal (67) o en el caso del ambiente gástrico, libre de factores inmunes, donde el Helicobacter pylori causa la úlcera péptica, patologías que parecen ceder al tratamiento, con la desaparición de los síntomas, pero cuando la terapia es retirada, las células persistentes restablecen el biofilm y por lo tanto la infección (68).

Estudios in vitro han permitido clarificar que la persistencia bacteria no se genera por mutación espontánea sino como un factor que se hereda y se afecta por la expresión de ciertos genes como hip, vncS, identificados en E coli y Streptococcus pneumoniae $(67,68)$.

Eliminación del biofilm: conociendo las causas de la resistencia del biofilm se han propuesto el desarrollo de medicamentos que eviten la adherencia o inhiban la persistencia, teniendo como blanco a los genes responsables de la expresión de estas características, pero esto no es fácil, ya que ellos varían en las diferentes especies haciendo que el pronóstico de un tratamiento universal de la infección por biofilm sea poco alentador en un futuro inmediato (69).

Sin embargo, mientras estos medicamentos se producen, se deben implementar medidas para prevenir la infección causada por el biofilm. La única terapia específica conocida se basa en la incorporación de antibióticos en los materiales del catéter, la combinación de Rifampicina y Minocyclina es especialmente 
NOVA - PUBLICACIÓN CIENTÍFICA ISSN:1794-2370 VOL.2 No. 2 ENERO- DICIEMBRE DE 2004:1-108

efectiva disminuyendo la posibilidad de colonización y es en esencia una medida profiláctica, esta tiene limitaciones; bacterias resistentes al antibiótico impregnado pueden colonizar el catéter y el método debe limitarse solo a catéteres que van a ser usados por corto tiempo y no es utilizable para prótesis y válvulas cardíacas $(70)$.

Dos métodos físicos para la erradicación del biofilm han sido propuestos; el uso de un campo electromagnético y el uso del ultrasonido, ambos unidos al uso de antibióticos parecen ser un promisorio método para el tratamiento del biofilm $(71,72)$.

Una solución simple que se ha planteado para el tratamiento del biofilm es la administración racional de un ciclo de antibióticos, retirarlos y volver a otro ciclo. La primera aplicación erradica la masa de células del biofilm separándolo de las células persistentes. Se retira el antibiótico, para dar la oportunidad a las células de restablecer el biofilm y se aplica una nueva dosis del antibiótico el cual destruirá totalmente el biofilm regenerado. La explicación que sustenta este tratamiento se basa en la observación que la persistencia disminuye de generación en generación (64). Esta propuesta se ha aprovechado en infecciones donde aplicaciones tópicas del antibiótico pueden ser utilizadas (73-76).

Otra interesante posibilidad para la eliminación del biofilm, especialmente los formados en procesos industriales, es promover su autodestrucción generando condiciones que le resulten adversas como la limitación de nutrientes esenciales y por lo tanto de energía (74-76).

\section{Conclusiones}

Los microorganismos pueden tener una existencia planctónica independiente, pero también pueden tener un ciclo de vida interdependiente en el cual funcionan como una parte integral de un sistema biológico con un alto nivel de organización formando estructuras coordinadas y comunidades funcionales.

Muchas de estas comunidades juegan un papel importante en la infección, entender el comportamiento del biofilm permitirá un mejor manejo de las patologías que él causa, así como la implementación de medidas que conduzcan a su prevención y a la generación de medicamentos para su tratamiento.

\section{Referencias}

1. March PD. Microbiologic aspects of dental plaque and dental caries. Dent.Clin.N. Am 1999; 43:599-614.

2. Costerton JW, Cheng G, Gersey TI, Ladd JG, Nickel M. Bacterial biofilms in nature and disease. Annu.Rev.MIcrobiol 1987; 41:435-64.

3. Ophir T, Gutnick DL. A papele for exopolysaccharide in the protection of microorganisms from desiccation. Appl. Environ. Microbiol 1994; 60:740-5.

4. O'Toole GA, Kolter R. The initiation of biofilm formation in Pseudomonas fluorescens WCS365 proceeds via multiple, convergent signaling pathways: a genetic analysis. Mol. Microbiol 1998;28:449-61.

5. Poulsen LK, Ballard G, Stahl DA. Use of rRNA fluorescence in situ hybridization for measuring the activity of single cells in young and established biofilms. Appl. Environ. Microbiol 1993; 59:1354-60.

6. Stanley PM. Factors affecting the irreversible attachment of Pseudomonas aeruginosa to stainless steel. Can. J. Microbiol 1983; 29:1493-9

7. Stickler, DJ, King JB, Winters C, Morris SL. Blockage of urethral catheters by bacterial biofilms. J. Infect 1993; 27:133-5.

8. Costerton JW, Zlewandoski ED, Caldwell DR, Lappin- Scott HM. Microbial biofilms. Annu.Rev. Microbiol 1995; 49: 71145 .

9. Caldwell DE. Cultivación and study of biofilm communites. In H.M. Microbial biofilms. Editors Lappin Scott and J.W. Costerton. Cambridge: University Press, U.K; 1995. p. 6479.

10. Henrischsen J. Bacterial surface traslocation: a survey and a classificaction. Microbiol. Rev 1972; 36:478-503.

11. Pratt LA, Kolter R. Genetic analysis of Escherichia coli biofilm formation: papeles of flagella, motility, chemotaxis and type I pili. Mol. Microbiol 1998; 30:285-93.

12. Watnick PI, Kolter R. Steps in the development of a Vibrio cholerae biofilm. Mol. Microbiol 1999; 34:586-95.

13. Davies DG, Chakrabarty AM, Geesey GG. Exopolysaccharide production in biofilms: substratum activation of alginate gene expression by Pseudomonas aeruginosa. Appl. Environ. Microbiol 1993; 59:1181-6.

14. Gacesa P. Bacterial alginate biosynthesisrecent progress and future prospects. Microbiology 1998; 144:1133-43.

15. Garrett, ES, Perlegas D, Wozniak DJ. Negative contpapel of flagellum synthesis in Pseudomonas aeruginosa is modulated by the alternative sigma factor $\mathrm{AlgT}(\mathrm{AlgU})$. J. Bacteriol 1999; 181:7401-4.

16. Pruzzo C, Crippa A, Bertone SL, Carli A. Attachment of Vibrio alginolyticus to chitin mediated by chitin-binding proteins. Microbiology 1996; 142:2181-6.

17. Overmann J, Pfennig N. Buoyancy regulation and aggregate formation in Amoebobacter purpureus from Mahoney Lake. Pems Microbiol Ecol 1992; 101:67-79.

18. Bazylinsky DA. Structure and function of de bacterial masgnetosome. ASM News 1995;61:337-43.

19. Caldwell DE, Atuku DC, Wilkie KP, Wivcharuk SK, Arthiken $\mathrm{D}$, Kobert DF, et al. Germ theory vs. community theory in understating and cotpapelling the ppapeliferation of biofilms. Adv.Dent.Res 1997;11: 13

www.unicolmayor.edu.co 
20. Anderson RN, Ganeshkumar N, Kolenbrander PE. Cloning of the Streptococcus gordonii PK488 gene, encoding an adhesin which mediates coaggregation with Actiomyces naselundii PK606. Infect Immun 1993; 61:981-7.

21. Kolenbrander PE, Anderson RN. Characterization of Streptococcus gordonii (S. sanguis) PK488 adhesion-mediated coaggregation with Actinomyces naeslundii PK606. Infect Immun 1990;58:3064-307.

22. Correia FF, DiRienzo JM, McKay TL, Rosan B. scbA from Streptococcus crista CC5A: an atypical member of the IraI gene family. Infect Immun 1996; 64:2114-21.

23. Sato Y, Yamamoto Y, Kizaki H. Cloning and sequence analysis of the gbpC gene encoding a novel glucan-binding protein of Streptococcus mutans. Infect Immun 1997; 65:668-75.

24. Ganeshkumar N, Hannam PM, Kolenrander PE, McBride BC. Nucleotide sequence of a gene coding for a saliva-binding protein $(\mathrm{SsaB})$ from Streptococcus sanguis 12 and possible papele of the protein in coaggregation with actinomyces. Infect Immun 1991; 59:1093-99.

25. Ganeshkumar N, Song M, McBride BC. Cloning of a Streptococcus sanguis adhesin which mediates binding to saliva-coated hydroxyapatite. Infect Immun 1988; 56:1150-7.

26. Sutherland JW. Biosynthesis and composition of gramnegative bacterial extracellular and wall polysaccharides. Annu. Rev. Microbiol 1985; 39:243-70.

27. Bellin CA, Rao PS. Impact of bacterial biomass on contaminant sorption and transport in a subsurface soil. Appl. Environ. Microbiol 1993; 59:1813-20.

28. Gilbert P, Das J, Foley I. Biofilms susceptibility to antimicrobials. Adv. Dent. Res. 1997; 11:160-7.

29. Neu TR, Verkerke GJ, Herrmann IF, Schutte HK, Van der Mei HC, Busscher HJ. Microflora on explanted silicone rubber voice protheses: taxonomy, hydrophobicity and electrophoretic mobility. J. Appl. Bacteriol 1994; 76:521-8.

30. Nichols WW, Dorrington SM, Slack MP, Walmsley HL. Inhibition of tobramycin diffusion by binding to alginate. Antimicrob. Agents Chemother 1988; 32:518-23.

31. Danese PN, Pratt LA, Kolter R. Exopolysaccharide production is required for development of Escherichia coli K-12 biofilm architecture. J. Bacteriol 2000; 182:3593-6.

32. Decho AW. Microbial exopolymer secretions in ocean environments: their papele(s) in food webs and marine processes. Oceanogr. Mar. Biol. Annu. Rev 1990; 28:73-153.

33. Flemming HC. Biofilms and environmental protection. Water Sci. Technol. 1993; 27:1-10.

34. Stoodley P, Boyle JD, Dodds I, Lappin-Scott HM. Consensus model of biofilm structure, In J. W. T. Wimpenny, P. S. Handley, P. Gilbert, H. M. Lappin-Scott, and M. Jones (ed.), Biofilms: community interactions and contpapels. BioLine, Cardiff, U.K; 1997. p. 1-9.

35. Davey ME, O'toole GA. Microbial Biofilms: from Ecology to Molecular Genetics. Microbiology and Molecular Biology Reviews 2000; 64(4): 1092-2172.

36. Hirsch P. Microcolony formation and consortia. In K. C. Marshall (ed.), Microbial adhesion and aggregation. Springer, Berlin: Germany; 1984. p. 373-393

37. MacLeod F A, Guiot SR, Costerton JW. Layered structure of bacterial aggregates produced in an upflow anaerobic sludge bed and filter reactor. Appl. Environ. Microbiol 1990; 56:1598-607.

38. Davies DG, Parsek MR, Pearson JP, Iglewski BH, Costerton JW, Greenberg EP. The involvement of cell-to-cell signals in the development of a bacterial biofilm. Science 1998; 280:295-8.

39. Davies J. Inactivation of antibiotics and the dissemination of resistance genes. Science 1994; 264:375-82.

40. Bergh OK, Borsheim Y, Bratbak G, Heldal M. High abundance of viruses found in aquatic environments. Nature 1989; $340: 467-8$
41. Proctor LM, Fuhrman JA. Viral mortality of marine bacteria and cyanobacteria. Nature 1990; 343:60-2.

42. Gilbert P, Das J, Foley I. Biofilms susceptibility to antimicrobials. Adv. Dent. Res 1997; 11:160-7.

43. Collins FS. Cystic fibrosis: molecular biology and therapeutic implications. Science 1992; 256:774-9.

44. Pier G. Pseudomonas aeruginosa: a key problem in cystic fibrosis. ASM News 64:339-47.

45. Hoyle BD, Jass J, Costerton JW. The biofilm glycocalyx as a resistance factor. J. Antimicrob. Chemother 1990;26:1-5.

46. Von Eiff C, Heilmann C, Peters G. New aspects in the molecular basis of polymer-associated infections due to staphylococci. Eur. J. Clin. Microbiol Infect. Dis 1999; 18:843-6.

47. Dingman JR, Rayner MG, Mishra S, Zhang Y, Ehrlich MD, Post JC, et al. Correlation between presence of viable bacteria and presence of endotoxin in middle-ear effusions. J. Clin. Microbiol 1998; 36:3417-9.

48. Brooks W, Demuth DR, Gil S, Lamont RJ. Identification of a Streptococcus gordonii $\mathrm{SspB}$ domain that mediates adhesion to Porphyromonas gingivalis. Infect. Immun 1997; 65:37533758 .

49. Doolittle MM, Cooney JJ, Caldwell DE. Lytic infection of Escherichia coli biofilms by bacteriophage T4. Can. J. Microbiol 1995; 41:12-8.

50. Lamont RJ, Jenkinson H F. Life below the gum line: pathogenic mechanisms of Porphyromonas gingivalis. Microbiol. Mol. Biol. Rev 1998; 62:1244-63.

51. Anwar H, Starp JL, Costerton WJ. Establishment of aging biofilms: possible mechanism of bacterial resistance to antimicrobial therapy. Antimicrob. Agents. Chemother 1992; 36:1347-51.

52. Hyde JA, Darouiche RO, Costerton J W. Strategies for prophylaxis against prosthetic valve endocarditis: a review article. J. Heart Valve Dis 1998; 7:316-26.

53. Elder MJ, Stapleton F, Evans E, Dart JK. Biofilm-related infections in ophthalmology. Eye. 1995; 9:102-9.

54. Gorlin AI, Gabriel MM, Wilson LA, Ahearn DG. Effect of adhered bacteria on the binding of Acanthamoeba to hydrogel lenses. Arch. Ophthalmol 1996; 114:576-80.

55. McLaughlin-Borlace L, Stapleton F, Matheson M, Dart JK. Bacterial biofilm on contact lenses and lens storgae cases in wearers with microbial keratitis. J. Appl. Microbiol 1998; 84:827-38

56. Kim L. Riddle of Biofilm Recistencia. Antimicrobial Agents and Chemotherapy 2001; $999-1007$.

57. Gordon CA, NA Hodges, Marriott C. Antibiotic interaction and diffusion through alginate and exopolysaccharide of cystic fibrosis-derived Pseudomonas aeruginosa. J. Antimicrob. Chemother 1988; 22: 667-74.

58. Anderl JN, Franklin MJ, Stewart PS. Papele of antibiotic penetration limitation in Klebsiella pneumoniae biofilm resistance to ampicillin and ciprofloxacin. Antimicrob. Agents Chemother 2000; 44: 1818 -24.

59. Dunne WM, Mason E0, KaplanSL. Diffusion of rifampin and vancomycin through a Staphylococcus epidermidis biofilm. Antimicrob. Agents Chemother. 1993; 37: 2522-6.

60. Darouiche RO, Dhir A, Miller AJ, Landon GC, Raad I, Musher D. Vancomycin penetration into biofilm covering infected prostheses and effect on bacteria. J. Infect. Dis 1994; 170: $720-3$.

61. Xu KD, McFeters GA, Stewart PS. Biofilm resistance to antimicrobial agents. Microbiology 2000; 146: 547-9.

62. Venglarcik JS, Blair LL, Dunkle LM. pH-dependent oxacillin tolerance of Staphylococcus aureus. Antimicrob. Agents Chemother 1983; 23:232-5. 
63. Brooun A, Liu S, Lewis K. A dose-response study of antibiotic resistance in Pseudomonas aeruginosa biofilms. Antimicrob. Agents Chemother 2000; 44:640-6.

64. Costerton JW, Stewart PS, Greenberg EP. Bacterial biofilms: A common cause of persistent infections. Science 1999; 284:1318-22.

65. Lewis K. Riddle of biofilm resistance. Antimicrob. Agents Chemother 2001; 45: 999-1007.

66. Novak R, Henriques B, Charpentier E, Normark S, Tuomanen E. Emergence of vancomycin tolerance in Streptococcus pneumoniae. Nature 1999; 399:590-3

67. Smith JG, Kong L, Abruzzo GK, Gill CJ, Flattery AM, Scott $\mathrm{PM}$, et al. Evaluation of experimental therapeutics in a new mouse model of Helicobacter felis utilizing 16S rRNA polymerase chain reaction for detection. Scand. J. Gastroentepapel 1997; 32:297-302.

68. Stermitz FR, Lorenz P, Tawara JN, Zenewicz L, Lewis K Synergy in a medicinal plant: antimicrobial action of berberine potentiated by 5 '-methoxyhydnocarpin, a multidrug pump inhibitor. Proc. Natl. Acad. Sci. USA 2000; 97:1433-7.

69. Darouiche RO, Smith JA, Hanna H, Dhabuwala CB, Steiner MS, Babaian RJ, et al. Efficacy of antimicrobial-impregnated bladder catheters in reducing catheter-associated bacteriuria: a prospective, randomized, multicenter clinical trial. Upapelogy 1999; 54:976-81.

70. McLeod BR, Fortun S, Costerton, JW, Stewart PS. Enhanced bacterial biofilm contpapel using electromagnetic fields in combination with antibiotics. Methods Enzymol 1999; 310:656-70.

71. Rediske AM, Roeder BL, Nelson JL, Robison RL, Schaalje GB, Robison RA, et al. Pulsed ultrasound enhances the killing of Escherichia coli biofilms by aminoglycoside antibiotics in vivo. Antimicrob. Agents Chemother 2000; 44:771-2.

72. Bigger JW. Treatment of staphylococcal infections with penicillin. Lancet 1944 (ii):497-500.

73. Allison DG, Ruiz B, San Jose C, Jaspe A, Gilbert P. Extracellular products as mediators of the formation and detachment of Pseudomonas fluorescens biofilms. FEMS Microbiol. Lett 1998; 167:179-184.

74. Formación y estructura del biofilm. Disponible en: URL: www.alientoassist.com/libro/book_2.htm.

75. El biofilm maduro. Disponible en: URL: www.clermont.inra.fr/ proteome/images/7jbis.jpg.

Correspondencia: revistanova@unicolmayor.edu.co 